\title{
Degradation of high level m-cresol by zinc oxide as photocatalyst
}

\begin{abstract}
In this study, the high concentration of m-cresol as a sample of organic pollutants was degraded in the presence of zinc oxide and UV irradiation during $6 \mathrm{~h}$ at laboratory scales. The amount of photocatalyst, $\mathrm{pH}$ and $\mathrm{m}$-cresol concentration were considered as effective factors on the photodegradation. The demineralization of $\mathrm{m}$-cresol was measured by $\mathrm{UV}-\mathrm{V}$ is spectrophotometry while the total organic carbon-analyzer was used to determine the mineralization. The ultrahigh performance LC was used to identify probable intermediates. The results showed optimum condition at $\mathrm{pH} 7-9$, which is the natural $\mathrm{pH}$ of industrial wastewater. Moreover, $100 \%$ of $\mathrm{m}$-cresol was removed after $5 \mathrm{~h}$ of irradiation time, which is quite significant. The detected intermediates were 3,5-hydroxytoluene, 2,5-hydroxybenzaldehyde, and 3-hydroxy-benzaldehyde after $3 \mathrm{~h}$ of reaction time. Reusability of the photocatalyst showed insignificant reduction in the photo-catalytic performance. In conclusion, this investigation indicated high potential of zinc oxide suspension to remove high level concentration of $\mathrm{m}$-cresol under UV irradiation.
\end{abstract}

Keyword: Advanced oxidation process; Demineralization; Photochemistry; Photodegradation; Wastewater treatment 